\title{
Tonic Pain Experienced during Locomotor Training Impairs Retention Despite Normal Performance during Acquisition
}

\author{
Jason Bouffard, Laurent J. Bouyer, Jean-Sébastien Roy, and Catherine Mercier \\ Centre interdisciplinaire de recherche en réadaptation et intégration sociale, Québec City, Québec G1M 2S8, Canada, and Département de réadaptation, \\ Faculté de médecine, Université Laval, Québec City, Québec G1V 0A6, Canada
}

\begin{abstract}
Many patients are in pain when they receive gait training during rehabilitation. Based on animal studies, it has been proposed that central sensitization associated to nociception (maladaptive plasticity) and plasticity related to the sensorimotor learning (adaptive plasticity) share similar neural mechanisms and compete with each other. The aim of this study was to evaluate whether experimental tonic pain influences motor learning (acquisition and next-day retention) of a new locomotor task. Thirty healthy human subjects performed a locomotor adaptation task (perturbing force field applied to the ankle during swing using a robotized orthosis) on 2 consecutive days. Learning was assessed using kinematic measures (peak and mean absolute plantarflexion errors) and electromyographic (EMG) activity. Half of the participants performed the locomotor adaptation task with pain on Day 1 (capsaicin cream around the ankle), while the task was performed pain-free for all subjects on Day 2 to assess retention. Pain had no significant effect on baseline gait parameters nor on performance during the locomotor adaptation task (for either kinematic or EMG measures) on Day 1. Despite this apparently normal motor acquisition, pain-free Day 2 performance was markedly and significantly impaired in the Pain group, indicating that pain during training had an impact on the retention of motor memories (interfering with consolidation and/or retrieval). These results suggest that the same motor rehabilitation intervention could be less effective if administered in the presence of pain.
\end{abstract}

Key words: experimental pain; gait; motor learning; motor performance; plasticity; rehabilitation

\section{Introduction}

Many people undergoing intensive rehabilitation simultaneously present pain and motor deficits limiting their function. While motor deficits are sometimes related to pain (e.g., avoidance/ compensation behaviors in musculoskeletal injuries), in other cases there is no evidence of a direct relationship between these two problems. For example, patients with spinal cord injury (SCI) consistently report that decreased ability to walk and pain are the two most difficult problems to manage (WiderströmNoga et al., 1999), particularly in cases of below-lesion neuropathic pain (Siddall et al., 1999), but these two aspects are typically addressed as independent problems. There is mounting evidence, however, that pain affects motor control and interacts with neural activity in motor pathways (Hodges and Tucker, 2011; Mercier and Léonard, 2011; Bank et al., 2013). Gaining a

Received Dec. 18, 2013; revised April 16, 2014; accepted May 18, 2014.

Author contributions: J.B., J.-S.R., L.J.B., and C.M. designed research; J.B. and L.J.B. performed research; J.B., J.-S.R., L.J.B., and C.M. analyzed data; J.B., J.-S.R., L.J.B., and C.M. wrote the paper.

This work was supported by an operating grant from the Canadian Institutes of Health Research (CIHR; MOP125869). J.B. was supported by studentships from the Fonds de recherche du Québec—Santé (FRQS), CIHR, and Institut de recherche Robert-Sauvé en santé et en sécurité du travail. J.-S.R. was supported by a salary award from the FRQS. C.M. was supported by salary awards from the CIHR and FRQS. We thank Mathieu Baril and Steve Forest for technical development and help with data collection.

The authors declare no competing financial interests.

This article is freely available online through the J Neurosci Author Open Choice option.

Correspondence should be addressed to Catherine Mercier, Centre interdisciplinaire de recherche en réadaptation et intégration sociale (CIRRIS), 525 boul. Hamel, Québec City, Quebec G1M 258, Canada. E-mail address: catherine.mercier@rea.ulaval.ca.

DOI:10.1523/JNEUROSCI.5303-13.2014

Copyright $\odot 2014$ the authors $\quad 0270-6474 / 14 / 339190-06 \$ 15.00 / 0$ better understanding of the influence of pain on response to gait training is essential to provide the most effective rehabilitation interventions.

Training-induced gait recovery following a lesion is known to involve adaptive plasticity in the spinal cord (Carrier et al., 1997; Whelan and Pearson, 1997; Bouyer et al., 2001; Rossignol and Bouyer, 2004). Repeated exposure to pain has also been shown to induce plasticity in the spinal cord, a phenomenon called central sensitization (Woolf, 2011). It has been proposed that spinal plasticity associated with central sensitization and with motor training share similar neural mechanisms and may interact with each other (Ferguson et al., 2012b). This hypothesis is supported by animal studies showing that exposure to uncontrollable nociceptive stimulation can inhibit adaptive spinal learning in spinalized rats (Crown et al., 2002; Ferguson et al., 2006, 2012a; Hook et al., 2008) and locomotor recovery following spinal concussion (Grau et al., 2004). While these results are very important, they cannot be directly transferred to clinical practice for two main reasons: (1) gait rehabilitation is typically performed in patients with incomplete SCI, and thus the contribution of supraspinal structures needs to be taken into account; and (2) the learning protocol used in these animal studies was very different (involving nociceptive stimuli) from locomotor training performed in rehabilitation.

To date, very few studies have investigated the effect of pain on motor learning in humans. Capsaicin-induced pain has been shown to prevent improvement in performance within a single training session in a tongue tracking task (Boudreau et al., 2007, 
A

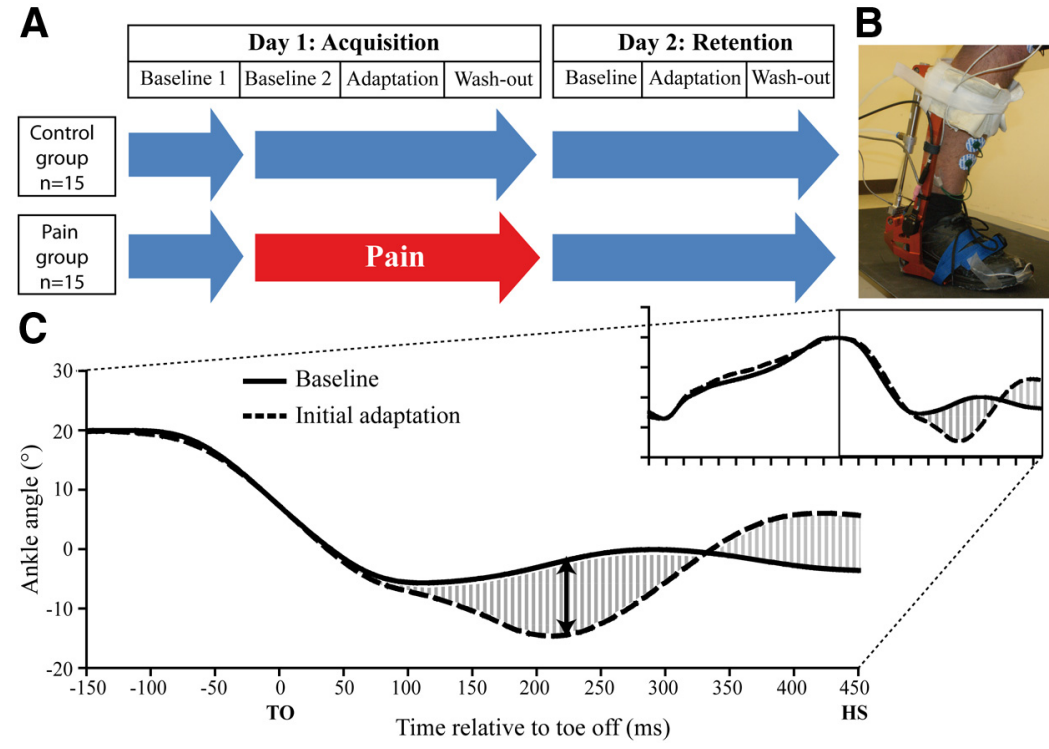

Figure 1. A, Experimental design. Blue arrows illustrate periods performed without pain while the red arrow illustrates the period performed with pain. B, Picture of the robotized ankle-foot EHO. C, Ankle kinematics during baseline gait (filled line) and the first gait cycle with the perturbation (dashed line) for a representative subject. The mean absolute error (shaded area) and the peak plantarflexion error (black double-arrow) variables are illustrated on the graph. T0, Toe off; HS, heel strike.

trials (here gait cycles; Lam et al., 2006; Noble and Prentice, 2006; Emken et al., 2007; Gordon and Ferris, 2007; Blanchette and Bouyer, 2009; Noel et al., 2009; Savin et al., 2010; Blanchette et al., 2011), significant aftereffects (Lam et al., 2006; Noble and Prentice, 2006; Emken et al., 2007; Blanchette and Bouyer, 2009; Noel et al., 2009; Savin et al., 2010; Blanchette et al., 2011), catch trials effects (Lam et al., 2006; Noel et al., 2009), and next-day retention (Gordon and Ferris, 2007; Fortin et al., 2009).

The presence of aftereffects and next-day retention show that adapting gait to a force field can be used as a learning paradigm. Recent work has started to unravel the neural mechanism underlying this phenomenon. Singlepulse transcranial magnetic stimulation (TMS) studies have shown changes in motor-evoked potential (MEP) size during gait adaptation to a force field that cannot simply be explained by a change in motoneuron excitability, suggesting a role for supraspinal structures such as M1 in the adaptive process (Barthélemy et al., 2012; Zabukovec et al., 2013). Moreover a recent study has investigated the effect of lowfrequency (presumably inhibitory) repetitive TMS applied over M1, S1, and posterior parietal cortex (PPC) on force field adaptation of

2010). In contrast, performance after training in a simple finger task was unaltered by local pain induced by hypertonic saline injection (Ingham et al., 2011). While these studies provide important information regarding the effect of pain on the immediate effect of training, they offer only a partial picture of the learning process. Factors improving or decreasing short-term motor acquisition are not always predictive of motor retention (Richardson et al., 2006; Reis et al., 2009; Kantak and Winstein, 2012), and from a clinical perspective it is retention that matters most. The objective of this study was therefore to assess the effect of tonic experimental pain on the acquisition and next-day retention of a new locomotor task.

\section{Materials and Methods}

Thirty-two healthy human subjects were recruited through advertisement at the local university, and were randomly assigned to either a Control or Pain group. Two subjects experienced pain not related to the experimental pain stimulus during the experiment and were therefore excluded. Thus 30 subjects ( 15 of either sex) completed the study, 15 in each group. In the latter, pain was induced by topical application of $1 \%$ capsaicin cream around the ankle before the acquisition phase (Day 1). This tonic pain model was selected to mimic neuropathic pain, i.e., pain that is typically not triggered by specific movements (as opposed to musculoskeletal nociceptive pain). Subjects were excluded if they had any significant neurological or musculoskeletal disorder, if they had any pain at the time of the study, or if they were unable to achieve a natural and stable gait pattern on the treadmill with the robotized orthosis during baseline assessment. All participants provided their written informed consent before inclusion and the ethical review board of the Institut de réadaptation en déficience physique de Québec (Québec, Canada) approved the study.

Paradigm selected to assess motor learning. In this study, a force field adaptation paradigm was used to study motor learning during walking. This approach is very similar to what is frequently used in motor learning studies performed during reaching (Krakauer and Mazzoni, 2011): a limb segment is deviated from its normal trajectory using a robotic device, thereby forcing the participant to modify his motor commands to compensate for the imposed deviation to return toward normal movement trajectory. Force field adaptation during gait shows similar features as reaching adaptation, including a gradual error reduction over several gait (Choi et al., 2014). While repetitive TMS (rTMS) over S1 or PPC had no effect, disruption of $\mathrm{M} 1$ activity reduced aftereffects without affecting adaptation, further suggesting a role of M1 in retention of this motor learning during gait.

The involvement of spinal circuits in the control of walking and in locomotor recovery has also been extensively studied (for review, see Rossignol et al., 2006, 2011). Of particular interest here is the fact that even in the absence of descending control, spinal cats can detect and compensate for movement errors during walking induced after a peripheral nerve cut (Bouyer et al., 2001). These results suggest that the spinal circuitry could therefore participate to the adaptive process of movement error compensation, such as seen during force field adaptation (for review, see Bouyer, 2011).

Together, these behavioral and neurophysiological studies provide evidence that gait adaptation involves plasticity in both the motor cortex and the spinal cord. As mentioned in the Introduction, pain has been shown to interfere with activity of the motor system both at the level of the motor cortex and of the spinal cord. Force field adaptation could therefore be sensitive to potential interference effects from pain.

In addition, this approach can also be particularly useful to study locomotor rehabilitation in patient populations for two main reasons. First, this is in our view the controlled model of motor learning that is the closest to the challenges faced by the patients that have to relearn how to move after body alterations caused by a neural or musculoskeletal lesion (i.e., in a context of weakness/altered tone that is not evenly distributed across muscles, or of other musculoskeletal factors affecting limb dynamics). Second, the subject's task in a force field adaptation paradigm is to retrieve his own initial movement kinematics despite the perturbation applied. Therefore, it is especially well suited to compare motor learning ability across patients that may have different initial movement kinematics due to their motor impairments (therefore it will be possible to directly transfer the model used in this study on experimental pain to clinical studies in population with motor deficits and concurring pain).

Procedures. To assess both motor acquisition and retention, subjects were tested on 2 consecutive days (Fig. 1A). On each day, subjects walked on a treadmill wearing an electrohydraulic ankle-foot orthosis (EHO; Noël et al., 2008) on their dominant leg. On Day 1, they first walked for 10 min without any pain or perturbation to record baseline gait (Baseline 1). Then, a band of capsaicin cream $(1 \% ; 1 \mathrm{~cm}$ wide) was applied around the ankle of the subjects in the Pain group. From this point in the experiment, subjects had to rate their pain level every 3 min using a numerical 


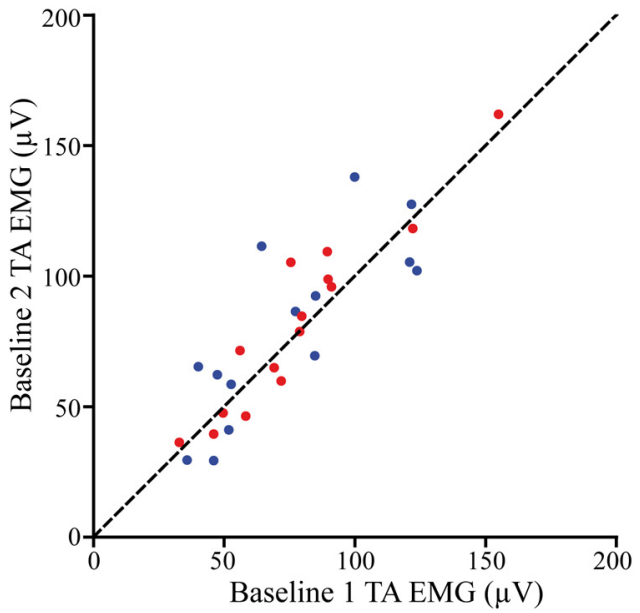

Figure 2. Mean stance-to-swing TA activation during Baseline 1 and Baseline 2 for each subject from the Control group (blue dots) and from the Pain group (red dots). The dashed line represents equal activation between the two walking sessions. Note that subjects from the Pain group experienced pain during the Baseline 2 period. It can be seen that pain did not change TA activation during baseline walking.

rating scale (NRS) until pain reached a plateau (typically after $\sim 30 \mathrm{~min}$ ). A wait period of $30 \mathrm{~min}$ was also imposed to the Control group. Thereafter, subjects of both groups walked for 10 min without any perturbation (Baseline 2), and then the perturbation was turned on unexpectedly and applied on each stride for $5 \mathrm{~min}$ (Adaptation). Finally, the perturbation was stopped unexpectedly and subjects continued to walk for $5 \mathrm{~min}$ (Wash-out). Considering that all subjects would have walked between the two testing sessions, a washout period was introduced to return gait kinematics to normal in a controlled manner before subjects left the laboratory. On Day 2, to assess retention, subjects performed three walking periods (Baseline, Adaptation, and Wash-out) and no pain was induced. The perturbation used was a parabolic shape torque applied by the EHO resisting dorsiflexion during midswing, with a peak intensity of $4.6 \pm 0.2 \mathrm{~N} \cdot \mathrm{m}$ and a $150 \mathrm{~ms}$ duration (Fig. $1 B, C$ ). Subjects were instructed to "fight the force to walk as normally as possible" (Blanchette et al., 2011). More details on the perturbation can be found in Blanchette et al. (2011).

Data acquisition. Ankle angular movements in the sagittal plane were recorded with an optical encoder located on the EHO. Tibialis anterior (TA) and soleus muscle activity was recorded using surface electromyography (EMG) using a custom-built amplifier (gain, 4000; bandpass filter, $10-500 \mathrm{~Hz}$ ). EMG electrodes (Kendall Meditrace 200, Covidien) were placed in bipolar configuration over the muscle belly, below the calf band of the robotized orthosis. Note that because of normalization issues, TA activity data were acquired only for Day 1 . A custom-made foot switch was placed under subjects' shoe to determine the beginning and the end of each gait cycle. All signals were recorded using custom software at 1000 samples/s. For the Pain group, pain intensity and unpleasantness were rated verbally with a NRS every 3 min before the beginning of the experiment (to ensure that a plateau was reached) and then at the beginning and the end of the gait adaptation paradigm (to verify whether pain remained constant throughout the experiment).

Data processing and analysis. All data processing was performed offline using custom software written in Matlab (Mathworks). A secondorder zero-lag $15 \mathrm{~Hz}$ low-pass digital filter was applied to the ankle optical encoder signal to remove noise. The EMG data were filtered with a second-order zero-lag $20-450 \mathrm{~Hz}$ bandpass digital filter and rectified. As the perturbation used in this study mainly produced changes in swing phase gait parameters, analysis focused on a period slightly larger than this phase, i.e., from the midpoint of the end-of-stance plantarflexion to the next heel strike. For the sake of simplicity and clarity, this analysis window will be referred to as the swing phase for the remaining of the article.
The analysis strategy was designed to answer three main questions: how does pain influence (1) baseline gait parameters, (2) initial acquisition of the locomotor adaptation task, and (3) $24 \mathrm{~h}$ retention? While descriptive data are provided for the whole time course of adaptation, the following time periods were selected for statistical analyses: Late Baseline 1 , mean of the last 10 strides of the Baseline 1 period; Late Baseline 2, mean of the last 10 strides of the Baseline 2 period; Initial Adaptation, first stride of the Adaptation period; Early Adaptation, mean of strides 2-11 of the Adaptation period; and Late Adaptation, mean of strides 191-200 of the Adaptation period.

For Late Adaptation, exact stride numbers were chosen rather than the last 10 strides to ensure that comparison could be made across participants (range of adaptation period duration: Control group, 220-270 strides; Pain group, 220-268 strides).

Effect of pain on baseline gait. The two baseline periods performed on Day 1 were used to test the effect of pain on baseline gait parameters. As the pain model used induced a tonic painful sensation unrelated to movement, there was no incentive to modify movement to avoid pain (Hodges and Tucker, 2011). Thus no effect of pain was expected on the baseline gait pattern. This was nevertheless verified here, as differences in baseline could have an impact on the comparison of motor learning between the Pain and Control groups.

A mean ankle angle curve was constructed using the last 100 strides of Baseline 1. This curve was then subtracted point-by-point from each Baseline 2 stride, providing a measure of the difference in relative ankle angle curves between Baseline 2 (with pain for the Pain group) and Baseline 1 (pain-free). The mean absolute value of this measure over the swing phase was used to compare the Pain and Control groups during Late Baseline 2 using an independent-samples $t$ test.

Rectified TA EMG was averaged for the last 10 strides of each baseline period. Mean TA activity during the stance-to-swing burst, which is the period of interest during the adaptation to the perturbation (Blanchette et al., 2011), was compared. A two-way repeated-measures ANOVA was performed to evaluate the between-group effect (Pain vs Control), and the within-group effects of Time (Late Baseline 1 vs Late Baseline 2) on TA EMG activity.

Effect of pain on acquisition and retention of motor learning. To determine the ability of subjects to adapt to the perturbation, a movement error signal was created. As for the baseline comparisons, an average ankle angular displacement curve was constructed from the mean of the last 100 Baseline 2 gait cycles and subtracted from each stride of the adaptation period. Two variables were extracted from this error signal: (1) a peak plantarflexion error (corresponding to the direction in which the force field pushed the foot) and (2) a mean absolute error for the whole swing phase, calculated by averaging the rectified error signal over the entire swing phase (Fig. 1C). To determine the effect of pain on acquisition and retention of the locomotor adaptation task, three-way repeated-measures ANOVAs were performed to evaluate the betweengroup effect (Pain vs Control), and the within-group effects of Day (1 vs 2) and Time (Early vs Late). Post hoc analyses were performed using a Sidak correction for multiple comparisons. As the force field was turned on unexpectedly and its magnitude was similar across days, the error on the first stride (Initial Adaptation) was not expected to change between days. To verify this, a two-way repeated-measures ANOVA was performed on Initial Adaptation data to evaluate the between-group effect (Pain vs Control), and the within-group effects of Day ( 1 vs 2 ). To gain further insight on the motor strategy used by both groups during adaptation, mean TA EMG activity during the stance-to-swing burst was calculated for each stride, and expressed as percentage of Baseline 2. A two-way repeated-measures ANOVA was performed to evaluate the between-group effect (Pain vs Control), and the within-group effects of Time (Early vs Late) on TA activity during the first day of the experiment. Descriptive statistics are presented in the text and in figures as mean \pm SEM.

\section{Results}

Subjects from the Control group $(26.1 \pm 2.1$ years, eight males) and subjects from the Pain group $(26.0 \pm 1.4$ years, seven males $)$ did not differ in term of age and sex. All subjects were right-foot 


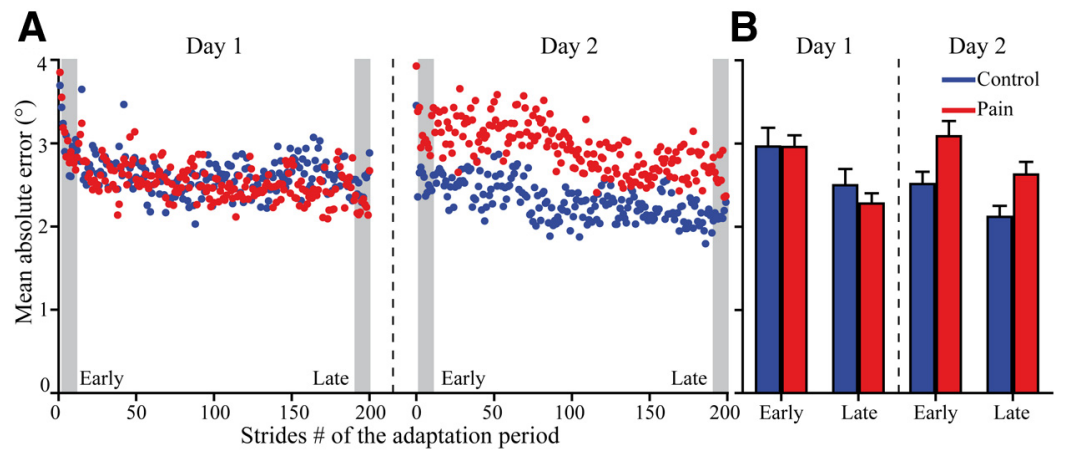

Figure 3. $\quad \boldsymbol{A}$, Time course of the mean absolute ankle angle error during the adaptation period of Days 1 and 2 for the Control (blue dots) and the Pain (red dots) groups. $\boldsymbol{B}$, Average values for the Early and Late Adaptation epochs ( $\boldsymbol{A}$, gray zones) on each day for both groups. These epochs were used for statistical analysis. Error bars represent SEM.

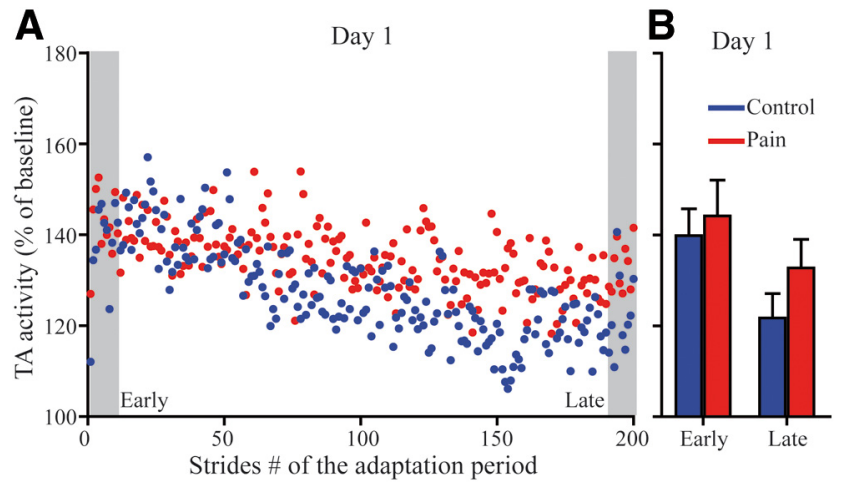

Figure 4. $\boldsymbol{A}$, Time course of TA EMG activity (stance-to-swing burst) during the adaptation period of Day 1 for the Control (blue dots) and the Pain (red dots) groups. $\boldsymbol{B}$, Average values for the Early and Late Adaptation epochs ( $\boldsymbol{A}$, gray zones) for both groups. These epochs were used for statistical analysis. Error bars represent SEM.

dominant according to the Waterloo footedness questionnaire (Elias et al., 1998). The application of capsaicin cream caused a moderate level of pain throughout the experiment. No significant change in pain intensity was observed over time $\left(t_{(14)}=2.041\right.$, $p=0.061$ ), although it tended to decrease slightly from the beginning of Baseline $2(4.8 \pm 0.4)$ to the end of the experiment $(3.9 \pm 0.7)$. No significant change was observed for unpleasantness either $\left(t_{(14)}=1.866, p=0.083\right)$.

\section{Effect of pain on baseline gait characteristics}

The mean absolute kinematic error between Baseline 2 and Baseline 1 was $2.04 \pm 0.96^{\circ}$ for the Control group and $1.81 \pm 0.85^{\circ}$ for the Pain group. There was no statistical difference between groups for this variable $\left(t_{(27)}=0.681, p=0.502\right)$. The ANOVA computed on baseline TA activity did not yield any significant difference between baseline periods and between groups either $\left(\right.$ all $\left.F_{(1,27)}<1.829, p>0.187\right)$. Figure 2 presents TA activity data during both baseline periods.

\section{Effect of pain on the acquisition and retention of motor learning}

Figure $3 A$ illustrates the time course of mean absolute kinematic error during force adaptation each day for both groups. Figure $3 B$ presents Early and Late Adaptation epochs each day. Subjects of both groups were able to significantly decrease the mean absolute kinematic error from Early to Late Adaptation on both days (main effect of Time: $\left.F_{(1,28)}=19.925, p=0.001\right)$. There was a significant Day $\times$ Group interaction $\left(F_{(1,28)}=7.704, p=0.01\right)$.
No other comparison was significant for this ANOVA. Post hoc analysis performed to better understand the Day $\times$ Group interaction show that a difference between groups was present when assessing the retention on Day $2(p=0.007)$, while no difference was observed between groups during the acquisition on Day 1 ( $p=$ 0.557). Mean absolute kinematic error during Initial Adaptation (i.e., the first stride when the force field was unexpectedly applied) was similar between days and groups (all $F_{(1,27)}<0.532 ; p>0.472$ ).

Regarding peak plantarflexion error, no main or interaction effect was significant from the ANOVA. Subjects quickly reduced their peak error, reaching a plateau within the early adaptation epoch $\left(\right.$ all $F_{(1,28)}<3.007 ; p>$ 0.094; data not shown).

Figure 4 illustrates TA EMG activity time course for Day 1 force field exposure, showing that subjects from both groups rapidly increased their TA activity in response to the force field. They then gradually stabilized at a lower plateau of activity, as previously reported in control subjects, probably seeking the most cost-effective strategy to perform the task (Blanchette et al., 2011). The results of the ANOVA highlight this behavior with a main effect of Time $\left(F_{(1,28)}=8.822, p=0.006\right)$, but no effect of Group or Group $\times$ Time interaction. Note that the lower plateau of TA activity observed late in the adaptation period remains over the baseline TA activity level.

\section{Discussion}

Results show that local tonic cutaneous pain interferes with the retention of a locomotor adaptation task despite the fact that baseline gait and motor acquisition were apparently unimpaired.

These first results on the effect of pain on retention of a motor task in humans are consistent with studies in spinalized rats that showed that nociceptive stimuli (uncontrollable electrical shocks or chemical compounds) can induce a learning deficit that outlasts the duration of stimulation (Crown et al., 2002; Ferguson et al., 2006, 2012a; Hook et al., 2008). Specifically, Hook et al. (2008) showed that subcutaneous injection of capsaicin following the acquisition of an instrumental learning task impaired the retention, which is similar to the results obtained in the present study. Interestingly, it has also been shown that the application of uncontrollable electrical stimulation early after inducing a spinal contusion in rats impaired their ability to recover locomotion over the following months (Grau et al., 2004).

The demonstration that learning deficits can also be induced in humans during walking, a task with a strong spinal control component, supports the important issue raised by these authors about the potential threat of nociceptive stimuli on the recovery potential following SCI (Ferguson et al., 2012b).

No differences were observed in baseline gait parameters after pain induction, which is in line with our hypothesis. Hodges and Tucker (2011) recently proposed a model to explain the interactions between pain and movement. Key features of this model are that pain interacts with the motor system at different levels in the CNS, leading to a nonstereotyped reorganization in motor behavior that may be driven by the objective of protecting the affected body part from further injury/pain. The painful stimulation used in the present study induced cutaneous tonic pain unrelated to movement. So, there was probably no way to adapt 
the motor performance to decrease this pain. This may explain the absence of impact of pain on baseline movement.

The fact that induction of tonic cutaneous pain around the ankle did not interfere with the acquisition of a new locomotor adaptation task within a training session is in line with previous results obtained during a simple finger movement task (Ingham et al., 2011). It, however, contradicts the results obtained with a tongue force production task, and with instrumental learning performed in spinal animals (Boudreau et al., 2007, 2010; Ingham et al., 2011). Those discrepancies might be explained by the use of different painful stimuli and motor tasks across studies. An important characteristic of the present study is that the locomotor task used imposed important constraints on the participants. First, subjects had to fight the perturbation as the EHO pushed the foot toward plantarflexion during the swing phase. Without any adaptation, they would potentially have tripped themselves, which created a strong incentive to adapt quickly. Conversely, gait pattern is highly influenced by the energetic cost of the task (Anderson and Pandy, 2001; Emken et al., 2007). Applying excessive forces to fight the force field would increase the energetic cost. The functional goals that were implicit to the task (i.e., safety vs energetic cost) may explain why the subjects performed well despite pain. Moreover, it is interesting to note that in the studies showing an impaired acquisition of the task in the presence of pain, the motor task in itself involved nociception. For example, in the instrumental learning task, animals had to modify their motor behavior to avoid a nociceptive electrical stimulation (Crown et al., 2002; Ferguson et al., 2006, 2012a; Hook et al., 2008). In the studies by Boudreau et al. $(2007,2010)$ the effector itself was sensitized with capsaicin and therefore performing the task may have produced an increase in pain. In fact, another study from this group showed that performing a similar tongue force production task in the absence of capsaicin caused pain by itself (pain rating of $\sim 2$ on a $0-10$ scale; Kothari et al., 2012). The implication of pain in the motor learning task per se may influence the effect of pain on motor learning.

Several mechanisms may have contributed to the lack of motor retention. First, several studies have highlighted the importance of the plastic potential of the spinal cord for locomotor learning (Carrier et al., 1997; Bouyer et al., 2001; Rossignol and Bouyer, 2004). Studies done in spinalized rats cited above clearly show that uncontrollable nociceptive stimulation interferes with this plastic potential of the spinal cord (Crown et al., 2002; Ferguson et al., 2006, 2012a; Hook et al., 2008). Furthermore, they showed that central sensitization associated to nociception (maladaptive plasticity) and spinal plasticity related to the learning task (adaptive plasticity) share similar neural mechanisms and compete with each other (for review, see Baumbauer et al., 2009; Ferguson et al., 2012b). Considering the important contribution of spinal networks in locomotion and the fact that capsaicin induces central sensitization (LaMotte et al., 1991; Kilo et al., 1994; Hook et al., 2008), this competitive plasticity within the spinal cord may have contributed to the observed decrease in retention.

In addition to the spinal cord plasticity, plasticity within the primary motor cortex is important for motor learning and more specifically for the motor retention. Studies have shown that modulation of motor cortex excitability with noninvasive brain stimulation can affect the retention of different motor learning tasks (Richardson et al., 2006; Reis and Fritsch, 2011). In a study by Richardson et al. (2006), low-frequency (inhibitory) rTMS applied before training in a visuomotor adaptation task interfered with retention while leaving the acquisition unimpaired, which is similar to our results. Studies focusing on the role of motor cortex in locomotor adaptation have looked exclusively at the motor acquisition phase. Barthélemy and collaborators (2012) showed with single-pulse TMS that M1 excitability is modulated when subjects adapt their behavior to different force fields affecting ankle movement during gait. In parallel, several studies showed that pain decreases corticospinal excitability, as illustrated by a pain-induced inhibition of motor responses evoked by single-pulse TMS applied to M1 as well as enhanced intracortical inhibition and decreased intracortical facilitation (Valeriani et al., 1999, 2001; Farina et al., 2001; Dubé and Mercier, 2011; Schabrun and Hodges, 2012). It is possible that pain exerts an effect that is quite similar to the inhibitory effects induced by low-frequency rTMS, and that this interference with motor cortex activity blocks the consolidation of motor memories. Future studies should include neuroimaging and neurostimulation techniques to provide more direct information on the cortical and spinal mechanisms underlying the impact of pain on the consolidation of motor memories. The comparison of tasks relying strongly on spinal control, such as locomotor tasks, versus tasks depending more on cortical control, such as reaching or manual tasks, would also help to understand how pain interacts with plasticity at different levels in the nervous system.

\section{Conclusion}

This study showed that cutaneous tonic pain induced by capsaicin cream impairs retention of a newly learned locomotor adaptation task, despite the fact that baseline gait parameters and improvement during the initial training session were not affected by pain. These results are consistent with the hypothesis that pain weakens the potential for plasticity at the level of the motor cortex and the spinal cord. As motor training is accompanied by pain in a variety of contexts, from the relearning of very simple everyday gestures in patients undergoing rehabilitation to the acquisition of highly skilled movement in elite athletes, the effect of pain on learning and plasticity is important to consider. The results of our study suggest that the same motor rehabilitation intervention could be less effective if administered in the presence of pain. However, further studies are needed to investigate the effect of different types of pain on the ability to learn different types of motor tasks.

\section{References}

Anderson FC, Pandy MG (2001) Dynamic optimization of human walking. J Biomech Eng 123:381-390. CrossRef Medline

Bank PJ, Peper CE, Marinus J, Beek PJ, van Hilten JJ (2013) Motor consequences of experimentally induced limb pain: a systematic review. Eur J Pain 17:145-157. CrossRef Medline

Barthélemy D, Alain S, Grey MJ, Nielsen JB, Bouyer LJ (2012) Rapid changes in corticospinal excitability during force field adaptation of human walking. Exp Brain Res 217:99-115. CrossRef Medline

Baumbauer KM, Young EE, Joynes RL (2009) Pain and learning in a spinal system: contradictory outcomes from common origins. Brain Res Rev 61:124-143. CrossRef Medline

Blanchette A, Bouyer LJ (2009) Timing-specific transfer of adapted muscle activity after walking in an elastic force field. J Neurophysiol 102:568 -577. CrossRef Medline

Blanchette A, Lambert S, Richards CL, Bouyer LJ (2011) Walking while resisting a perturbation: effects on ankle dorsiflexor activation during swing and potential for rehabilitation. Gait Posture 34:358-363. CrossRef Medline

Boudreau S, Romaniello A, Wang K, Svensson P, Sessle BJ, Arendt-Nielsen L (2007) The effects of intra-oral pain on motor cortex neuroplasticity associated with short-term novel tongue-protrusion training in humans. Pain 132:169-178. CrossRef Medline

Boudreau SA, Hennings K, Svensson P, Sessle BJ, Arendt-Nielsen L (2010) The effects of training time, sensory loss and pain on human motor learning. J Oral Rehabil 37:704-718. CrossRef Medline 
Bouyer LJ (2011) Chapter 8 - challenging the adaptive capacity of rhythmic movement control: from denervation to force field adaptation. Prog Brain Res 188:119-134. CrossRef Medline

Bouyer LJ, Whelan PJ, Pearson KG, Rossignol S (2001) Adaptive locomotor plasticity in chronic spinal cats after ankle extensors neurectomy. J Neurosci 21:3531-3541. Medline

Carrier L, Brustein E, Rossignol S (1997) Locomotion of the hindlimbs after neurectomy of ankle flexors in intact and spinal cats: model for the study of locomotor plasticity. J Neurophysiol 77:1979-1993. Medline

Choi JT, Bouyer LJ, Nielsen JB (2014) Disruption of locomotor adaptation with repetitive transcranial magnetic stimulation over the motor cortex. Cereb Cortex. Advance online publication. Retrieved May 27, 2104. Medline

Crown ED, Ferguson AR, Joynes RL, Grau JW (2002) Instrumental learning within the spinal cord: IV. Induction and retention of the behavioral deficit observed after noncontingent shock. Behav Neurosci 116:1032_ 1051. CrossRef Medline

Dubé JA, Mercier C (2011) Effect of pain and pain expectation on primary motor cortex excitability. Clin Neurophysiol 122:2318-2323. CrossRef Medline

Elias LJ, Bryden MP, Bulman-Fleming MB (1998) Footedness is a better predictor than is handedness of emotional lateralization. Neuropsychologia 36:37-43. CrossRef Medline

Emken JL, Benitez R, Sideris A, Bobrow JE, Reinkensmeyer DJ (2007) Motor adaptation as a greedy optimization of error and effort. J Neurophysiol 97:3997-4006. CrossRef Medline

Farina S, Valeriani M, Rosso T, Aglioti S, Tamburin S, Fiaschi A, Tinazzi M (2001) Transient inhibition of the human motor cortex by capsaicininduced pain. A study with transcranial magnetic stimulation. Neurosci Lett 314:97-101. CrossRef Medline

Ferguson AR, Crown ED, Grau JW (2006) Nociceptive plasticity inhibits adaptive learning in the spinal cord. Neuroscience 141:421-431. CrossRef Medline

Ferguson AR, Huie JR, Crown ED, Grau JW (2012a) Central nociceptive sensitization vs spinal cord training: opposing forms of plasticity that dictate function after complete spinal cord injury. Front Physiol 3:396. CrossRef Medline

Ferguson AR, Huie JR, Crown ED, Baumbauer KM, Hook MA, Garraway SM, Lee KH, Hoy KC, Grau JW (2012b) Maladaptive spinal plasticity opposes spinal learning and recovery in spinal cord injury. Front Physiol 3:399. CrossRef Medline

Fortin K, Blanchette A, McFadyen BJ, Bouyer LJ (2009) Effects of walking in a force field for varying durations on aftereffects and on next day performance. Exp Brain Res 199:145-155. CrossRef Medline

Gordon KE, Ferris DP (2007) Learning to walk with a robotic ankle exoskeleton. J Biomech 40:2636-2644. CrossRef Medline

Grau JW, Washburn SN, Hook MA, Ferguson AR, Crown ED, Garcia G, Bolding KA, Miranda RC (2004) Uncontrollable stimulation undermines recovery after spinal cord injury. J Neurotrauma 21:1795-1817. CrossRef Medline

Hodges PW, Tucker K (2011) Moving differently in pain: a new theory to explain the adaptation to pain. Pain 152:S90-98. CrossRef Medline

Hook MA, Huie JR, Grau JW (2008) Peripheral inflammation undermines the plasticity of the isolated spinal cord. Behav Neurosci 122:233-249. CrossRef Medline

Ingham D, Tucker KJ, Tsao H, Hodges PW (2011) The effect of pain on training-induced plasticity of the corticomotor system. Eur J Pain 15: 1028-1034. CrossRef Medline

Kantak SS, Winstein CJ (2012) Learning-performance distinction and memory processes for motor skills: a focused review and perspective. Behav Brain Res 228:219-231. CrossRef Medline

Kilo S, Schmelz M, Koltzenburg M, Handwerker HO (1994) Different patterns of hyperalgesia induced by experimental inflammation in human skin. Brain 117:385-396. CrossRef Medline

Kothari M, Svensson P, Huo X, Ghovanloo M, Baad-Hansen L (2012) Force and complexity of tongue task training influences behavioral measures of motor learning. Eur J Oral Sci 120:46-53. CrossRef Medline

Krakauer JW, Mazzoni P (2011) Human sensorimotor learning: adapta- tion, skill and beyond. Curr Opin Neurobiol 21:636-644. CrossRef Medline

Lam T, Anderschitz M, Dietz V (2006) Contribution of feedback and feedforward strategies to locomotor adaptations. J Neurophysiol 95:766-773. Medline

LaMotte RH, Shain CN, Simone DA, Tsai EF (1991) Neurogenic hyperalgesia: psychophysical studies of underlying mechanisms. J Neurophysiol 66:190-211. Medline

Mercier C, Léonard G (2011) Interactions between pain and the motor cortex: insights from research on phantom limb pain and complex regional pain syndrome. Physiother Can 63:305-314. CrossRef Medline

Noble JW, Prentice SD (2006) Adaptation to unilateral change in lower limb mechanical properties during human walking. Exp Brain Res 169:482495. CrossRef Medline

Noël M, Cantin B, Lambert S, Gosselin CM, Bouyer LJ (2008) An electrohydraulic actuated ankle foot orthosis to generate force fields and to test proprioceptive reflexes during human walking. IEEE Trans Neural Syst Rehabil Eng 16:390-399. Medline

Noel M, Fortin K, Bouyer LJ (2009) Using an electrohydraulic ankle foot orthosis to study modifications in feedforward control during locomotor adaptation to force fields applied in stance. J Neuroeng Rehabil 6:16-27. CrossRef Medline

Reis J, Fritsch B (2011) Modulation of motor performance and motor learning by transcranial direct current stimulation. Curr Opin Neurol 24:590 596. CrossRef Medline

Reis J, Schambra HM, Cohen LG, Buch ER, Fritsch B, Zarahn E, Celnik PA, Krakauer JW (2009) Noninvasive cortical stimulation enhances motor skill acquisition over multiple days through an effect on consolidation. Proc Natl Acad Sci U S A 106:1590-1595. CrossRef Medline

Richardson AG, Overduin SA, Valero-Cabré A, Padoa-Schioppa C, PascualLeone A, Bizzi E, Press DZ (2006) Disruption of primary motor cortex before learning impairs memory of movement dynamics. J Neurosci 26 : 12466-12470. CrossRef Medline

Rossignol S, Bouyer L (2004) Adaptive mechanisms of spinal locomotion in cats. Integr Comp Biol 44:71-79. CrossRef Medline

Rossignol S, Dubuc R, Gossard JP (2006) Dynamic sensorimotor interactions in locomotion. Physiol Rev 86:89-154. CrossRef Medline

Rossignol S, Frigon A, Barrière G, Martinez M, Barthélemy D, Bouyer L, Bélanger M, Provencher J, Chau C, Brustein E, Barbeau H, Giroux N, Marcoux J, Langlet C, Alluin O (2011) Chapter 16-spinal plasticity in the recovery of locomotion. Prog Brain Res 188:229-241. CrossRef Medline

Savin DN, Tseng SC, Morton SM (2010) Bilateral adaptation during locomotion following a unilaterally applied resistance to swing in nondisabled adults. J Neurophysiol 104:3600-3611. CrossRef Medline

Schabrun SM, Hodges PW (2012) Muscle pain differentially modulates short interval intracortical inhibition and intracortical facilitation in primary motor cortex. J Pain 13:187-194. CrossRef Medline

Siddall PJ, Taylor DA, McClelland JM, Rutkowski SB, Cousins MJ (1999) Pain report and the relationship of pain to physical factors in the first 6 months following spinal cord injury. Pain 81:187-197. CrossRef Medline

Valeriani M, Restuccia D, Di Lazzaro V, Oliviero A, Profice P, Le Pera D, Saturno E, Tonali P (1999) Inhibition of the human primary motor area by painful heat stimulation of the skin. Clin Neurophysiol 110:14751480. CrossRef Medline

Valeriani M, Restuccia D, Di Lazzaro V, Oliviero A, Le Pera D, Profice P, Saturno E, Tonali P (2001) Inhibition of biceps brachii muscle motor area by painful heat stimulation of the skin. Exp Brain Res 139:168-172. CrossRef Medline

Whelan PJ, Pearson KG (1997) Plasticity in reflex pathways controlling stepping in the cat. J Neurophysiol 78:1643-1650. Medline

Widerström-Noga EG, Felipe-Cuervo E, Broton JG, Duncan RC, Yezierski RP (1999) Perceived difficulty in dealing with consequences of spinal cord injury. Arch Phys Med Rehabil 80:580-586. CrossRef Medline

Woolf CJ (2011) Central sensitization: implications for the diagnosis and treatment of pain. Pain 152:S2-S15. CrossRef Medline

Zabukovec JR, Boyd LA, Linsdell MA, Lam T (2013) Changes in corticospinal excitability following adaptive modification to human walking. Exp Brain Res 226:557-564. CrossRef Medline 